\section{¿Es posible reducir la jornada laboral en Chile?}

Lucas Navarro, Ph.D. en Economía, Georgetown UniWersity Estados Unidos Director Magister en Economía, versity, Estados Unidos.Director Magis

Ante una nueva propuesta para reducir la jornada laboral legal de 45 a 40 horas sem las horas trabajadas? Distintos informes de la OCDE muestran que efectivamente Chile es uno de los paises con mavor número de holas trabajadas La tendencia internacional, en especial entre paises desarrollados, va hacia la reducción de la jornada legal de trabajo. Sin embargo, en el caso chileno se debe evaluar con mucho cuidado el impacto de una reducción importante en las horas laborales, ya que los efectos sobre el bienestar pueden terminar siendo negativos y por lo tanto contrarios a los que se buscan con esta medida. Existen argumentos a favor de reducir la jornada laboral, fundamentados en evidencia para paises desarrollados. Estudios recientes (Rasposo y Van Ours, 2010) con datos de Portugal, tienden a mostrar que reducciones moderadas en la jornada tienen efectos nulos Whasta positivos en empleo via menor destrucción de puestos de trabajo. Berniell y Bletenbeck (2017) consideran que contribuye fumar $y$ de inactividad fisica en los trabajadores franceses, $y$ Hamermesh et al (2014) -con datos de Japon y Corea del Sur- señaan que mejora el bienestar familiar ya que los trabajodores tiene más tiempo para sus familias. Otro estudio reciente para dicho pais oriental (Lee, 2016) encuentra un efecto positivo en la reducción de accidentes de trabajo, los que típicamente se asocian a un trabajo excesivo. Para el caso especifico de Chile, Sánchez (2013) no encuentra efectos en la reducción de la jornada laboral de 2005, que

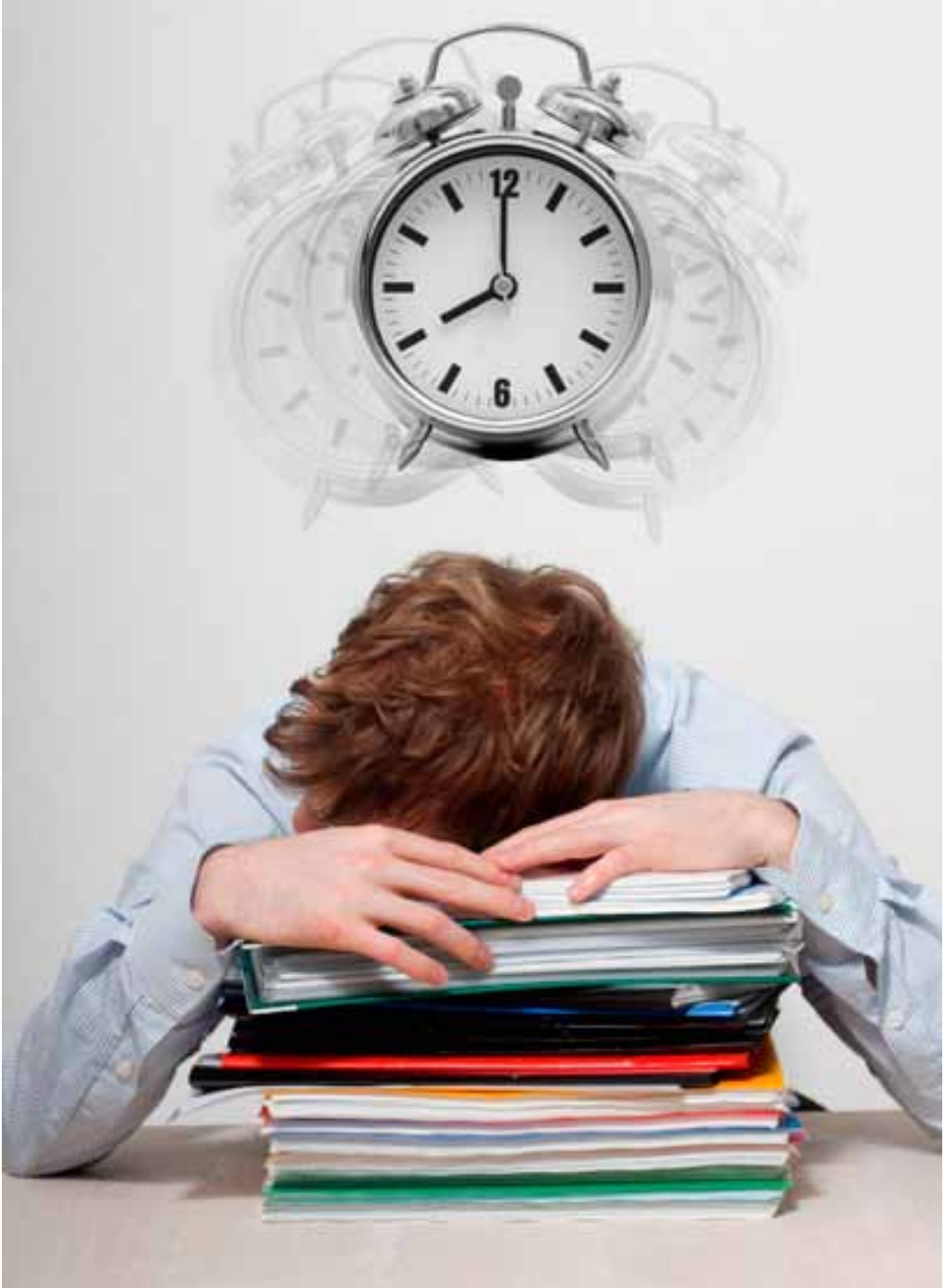

pasó de 48 a 45 horas semanales, y sólo detecta un efecto positivo

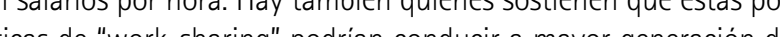
empleo (repartir un número de horas de trabajo menor entre más rabajades) aunque ta evidencia parece sugeri un efecto nulo 0 muy pequeño y tempora.

Para el caso de la propuesta de la diputada CamilaVallejos, se trata de una reducción de la jornada de 45 a 40 horas semanales, sin cambio proporcional en salarios totales. Esto equivale a un 作 actualmente cuentan con contratos de 45 horas semanales. Est succion implica un incremento relativo del salario horario muy superior al de $6.7 \%$ implicito que resultaba de la reduccion de jortoul legal anterior mplementada en Chile a partir de 2005. Por to anto el desafio es mucho mayor.

Jodrian evir las empresas este aumento en el costo laboral en L corto plazo? La unica forma de hacerlo seria que los trabajadores da de 45 horas semanales en una hor diaria menos de trabajo. ese caso ideal el aumento del salario horrio serí compensado por un aumento en productividad y la reducción de la jornada labora legal no tendría impactos mayores sobre el mercado laboral. Sin embargo, resultaría utópico esperar que todas las firmas pueda reaccionar de esta manera. Sin cambios efectivos en productividad esta reforma necesariamente implicará un aumento de los costos laborales para las empresas.
¿Cómo afectará esta politica al empleo? Suponiendo que antes y la reforma los trabajadores están con su productividad potencia y que con los cambios pasarán a trabajar menos horas, necesariamás trabajo por esas horas, por ejemplo pagando horas extra, I que tiene un costo laboral marginal mayor. Por otro lado, consider que ya por los trabajadores beneficiados con la medida, el salario por hora aumentaria $12.5 \%$. Esto significa que, sin aumentos en productividad, la reforma elevera el costo laboral para las empresas. Por tanto, se encontarán en dos situaciones alternativas:

1) Que esté en condiciones de financiar ese aumento de costos negativos de corto plazo en empleo, aunque si en sus posibilidades de inversión y crecimiento futuros. Más aún con el aumento de costos laborales las firmas tendrian incentivos a sustituir trabajo por capital, disminuyendo el empleo en el largo plazo.

2) Que no pueda financiar el aumento porque presenta márgenes de ganancias pequeños, con lo cual la medida podría generar destrucción de puestos de trabajo mediante despidos y cierre de plantas. enentarse esta portica? Lamentablemente para responder esta pregunta no se cuenta con la información y la evidencia suficiente. Necesitamos saber por ejemplo, en que medida los trabajadores son remunerados de acuerdo a su productividad. Existen muchos tra-

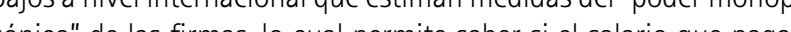
sónico" de las firmas, lo cual permite saber si el salario que pagan

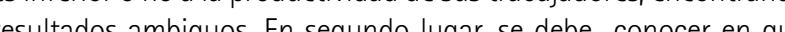
medida las horas de trabajo son excesivas en reción a las tareas que desarrollan los trabajadores. Si el número de horas de trabajo es excesivo, una reducción de la jornada hasta podría mejorar productividad por hora del trabajador. Prácticamente no hay estudios en Chile que hayan abordado estas preguntas.

Si se quiere debatir esta politica en profundidad, se debe contar además con información pertinente. Los paises desarrollados en los que se trabajan "pocas" horas, cuentan con bases de datos administrativos con informacion combinada de empleadores y trabajadores. Este tipo de información se viene usando en el mundo desde hace más de dos decadas y podria ser de especial de utilidad para evaluar el impacto de esta politica. En Chile esos datos existen pero no están disponibles. Con esa información se podria estudiar de mejor manera si los salarios realmente reflejan la productividad situación vuadores y que empresas/rabajadores se encontrarlan en por ejemplo, cuando se pasó a implementar la jornada de 35 horas semanales a comienzos de siglo, el gobierno implementó un sistema de subsidios compensatorios a empresas que se vieron muy comprometidas financieramente con la reducción de la jornada en especial las empresas pequeñas. Para el caso de Chile, si se aplicara esta reforma existe una alta incertidumbre sobre en qué medida los trabajadores se podrian ajustar a esa menor jornada sin compromeer el funcionamiento de las empresas.
¿Se dedicarán más a tareas recreativas y a pasar más tiempo con Sus familias y amigos? No necesariamente. Algunos de ellos tratron de usar ese - realiza todos los meses sobre las preferencias por duración la jornada laboral hay dos preguntas que resultan especialmente a por un sad y otra es si estaria dispuesto a trabajar menos horas por un salanio proporcional menor. Los trabajadores que contessatisfechos con la duración de su jortas serian los que estarian

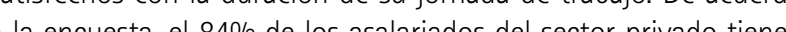
contrato y el 95\% de ellos trabaja a tiempo completo (en prome . que trabajan sus horas habituales de trabajo, los datos del último trimestre de 2015 (los últimos disponibles con información de ingresos) muestran que un 72,4\% estaria "satisfecho" con su jornada laboral, un 1,5\% querría reducir la jornada pero a cambio de un salario proporcionalmente menor, y un 26,1\% querria trabajar màs hras de trabajo. Obviamente que si se preguntara si estaria dis-

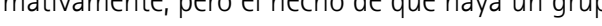
importante de trabajadores full-time dispuesto a trabajar más horas an tareas lo mover de esos trabajadores son no calificados, real-

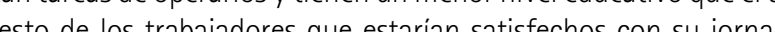
aboral El ingreso mensual de esos trabajadores es 20\% inferior que el del resto de los trabajadores considerados. Los datos de trimestre de 2016 muestran cifras de estos trabajadores que querian trabajar mas no requerian más horas o no les pagaban las horas extra. Más de un 8\% de estos trabajadores realizan una actividad secundaria para complementar sus ingresos. Esto sugiere que los ingresos laborales son insuficientes y eso es otro reflejo del problema de productividad de la economía loca.

En definitiva, hay que considerar que Chile es muy distinto a otros palses que han reducido significativamente la jonnada laboral y que presentan altos ingresos por habilante como Suecia, Holanda, Dinamarca. La diferencia es que esos paises son muchos más productivos vademás, pueden pagar salarios lo sufien muchos mas productivos mero de horas lativamente bajo. Si se quiere reduci los tiempos de tary par eso debe mejaradores los salios tienen que aumen-

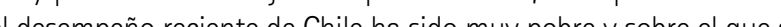
viene debatiendo intensamente. Para solventar politicas como estas, previamente se debe ser capaz de aumentar significativamente productividad e incrementar sueldos para asi elevar el nivel de vida de la población. Todavia, más de la mitad de los trabajadores chilenos ganan no más de dos salarios minimos. Parece positivo pensar en un objetivo de largo plazo de reducir las horas de trabajo, pero . do laboral en general. 